\title{
Care precarity among older British migrants in Spain
}

\author{
Kelly Hall (ic) \\ Department of Social Policy, Sociology and Criminology, University of Birmingham, Birmingham, UK \\ Email: k.j.hall@bham.ac.uk
}

(Accepted 2 September 2021)

\begin{abstract}
Northern European international retirement migrants are often viewed as affluent and use migration as a route to a better quality of life. However, as these migrants transition into the 'fourth age', the onset of age-related illnesses, frailty and care needs can lead to increased levels of risk and insecurity. Through 34 qualitative interviews with older British migrants in Spain, the paper explores how these migrants access and experience care as they age. It draws on a lens of precarity that allows an understanding not only of individual care needs, but of the political, economic and social context in which they are situated, including social protections and public safety nets. The findings suggest that distant family relationships and limited access to formal social protection can both create and exacerbate precarity. These older migrants therefore develop different strategies to access care that include drawing on informal relationships and voluntary organisations within the British community in Spain. The paper contributes to understanding how international retirement migrants manage their care needs, and theoretically extends our understanding of how the intersection of old age, migration and care can create new forms of precarity.
\end{abstract}

Keywords: international retirement migration; precarity; care; fourth age; Spain

\section{Introduction}

Northern European international retirement migrants (IRMs) are often viewed as affluent or privileged 'lifestyle' migrants (Benson and O'Reilly, 2009; Huete et al., 2013) who use migration as a route to a better quality of life. IRMs tend to migrate in the third age of life, shortly after retirement when they are healthy and active, and migration provides an opportunity to pursue 'active ageing' as part of a successful retirement strategy (Oliver, 2008). Spain remains the most popular retirement destination for British nationals and the Spanish 'Costas' are now home to large communities of older British people who are attracted by a better climate, a plethora of social activities and lower living costs (O'Reilly, 2000; Oliver, 2008). Most British migrants choose to reside in tourist destinations with good

(c) The Author(s), 2021. Published by Cambridge University Press. This is an Open Access article, distributed under the terms of the Creative Commons Attribution licence (http://creativecommons.org/licenses/by/4.0/), which permits unrestricted re-use, distribution and reproduction, provided the original article is properly cited. 
infrastructure, where there are large British (and other Northern European) communities and so there is little need to speak Spanish (O'Reilly, 2007, 2017). Retirement migration to Spain is therefore well established and around 117,000 British nationals receive their state pension in Spain (Benton, 2017). Some moved many years or even decades ago and have since transitioned into the 'fourth age' where the onset of age-related illnesses and increasing frailty means that they now need additional care and support (Oliver, 2008; Ahmed and Hall, 2016; Hall and Hardill, 2016).

Migration, however, presents a set of care-related challenges, with the transnational context restricting access to both informal and formal care systems. Care and support from family in the United Kingdom (UK) is restricted by distance, whilst in Spain, the social care system relies almost entirely on families. Publicly funded care in Spain is therefore limited and for British migrants, language and cultural barriers can further restrict access to Spanish social services and other local support (Gavanas and Calzada, 2016; Hall and Hardill, 2016; Calzada, 2017). A private care sector catering to the needs of British people is emerging in Spain (Gavanas, 2017); however, this market provision remains unaffordable for many older migrants. Consequently, there are increasing numbers of British people in Spain facing insecurity and risk as they age. This paper draws on a lens of precarity to understand how older British migrants access care and old-age support in Spain and to identify any care gaps that they face.

To date, the majority of research on retirement migration to Spain has explored access to health care, as well as the informal support networks that retirees have when they are healthy and active. Instead, this paper focuses on how British IRMs negotiate their care needs as they age and their ability for independent living declines and frailty sets in. Prior research (Hall and Hardill, 2016) has explored individual experiences of vulnerability and frailty among IRMs; however, this paper instead uses a precarity lens that situates individual experiences of risk and insecurity within a broader social, economic and political context. The paper combines and extends existing bodies of literature on precarity in relation to the migrant experience (Arun et al., 2020) and ageing experience (Grenier, 2020), and in turn enables a stronger understanding of how the intersection of old age and migration can create new forms of precarity that have not been previously identified.

The paper draws on 34 qualitative interviews with British IRMs in Spain to seek to answers the question: 'how do older British migrants in Spain access care'? The emerging narratives demonstrate how care-related precarity lies at the intersection of public, private and informal care systems. It focuses on three core dimensions of precarity: political, economic and social. Following this brief introduction, the paper provides an overview of what is already known about care for IRMs in Spain before situating this within a precarity framework. It then outlines the methodology before presenting the findings that demonstrate the political, economic and social dimensions of precarity among IRMs.

\section{Caring for British IRMs in Spain}

The transnational lives of British IRMs in Spain are situated within and between the home (UK) and host (Spanish) welfare states. British nationals are able to export 
their pension (including any uprating) and health-care rights to any European Union (EU) country. British state pensioners therefore lose access to the British National Health Service, but are entitled to free health care in Spain to the same level as a Spanish national. Health-care costs are organised on a reciprocal basis, so the UK government reimburses any incurred (state) health-care costs (Benton, 2017). Research suggests that British IRM experiences of health-care services in Spain are largely positive, despite cultural and language barriers (Legido-Quigley and McKee, 2012; Hall and Hardill, 2016). Under the European Union (Withdrawal Agreement) Act 2020, British migrants who were legally resident in Spain by 31 December 2020 may also receive some UK welfare benefits including Attendance Allowance and Disability Living Allowance, although most other benefits including Pension Credit and Winter Fuel Payments (which became nonexportable to Spain in 2015) are not exportable. Whilst ongoing rights to reciprocal health care and uprated pensions have been secured for all British pensioners living in the EU post-Brexit, some welfare rights (e.g. the exportability of Attendance Allowance) have been withdrawn for those who migrated after 31 December 2020.

Access to social care in Spain is determined through residency rather than reciprocal arrangements. British nationals in Spain are entitled to use Spanish social services as long as they have been resident for at least five years (Calzada, 2017). Spain, however, has one of the lowest levels of state-funded care provision in Europe (Gavanas, 2017). Compared to the UK, care services in Spain, particularly community/home-based care, are sparse due to the continued 'familistic' welfare model (León and Migliavacca, 2013) that has an almost complete reliance on the family for care. Public social care provision was reformed in 2007 with the introduction of the 'Ley de Dependencia' (known as the 'Dependency Law') that attempted to establish universal coverage, but 'fiscal consolidation policies' imposed after the 2008/2009 economic crisis meant the programme was delayed and faced cuts, particularly for those with lower levels of need (Rodríguez Cabrero et al., 2018).

For IRMs, language and cultural barriers further limit access to Spanish social services. It has been widely noted that few retired migrants from the UK and other Northern European countries speak Spanish (despite many trying to learn) (Hardill et al., 2005; Casado-Diaz, 2006; Hall and Hardill, 2016), and Spanish social workers rarely speak fluent English (Calzada, 2017). Whilst research in this area is sparse, Calzada's (2017) study of Swedish IRMs and social service providers in Spain suggests that most Northern European IRMs are reluctant to approach Spanish social services due to language barriers. The study notes that due to familistic principles, Spanish social services are designed to provide extra help for family care-givers and so are not adequate to meet the needs of most IRMs who have little or no family nearby.

There is a growing sector of privately hired domestic and care workers in Spain. In much of Southern Europe, globalised migration patterns have established a large migrant care worker market that acts as a means to sustain the ideal of family care (Michel and Peng, 2012). Spain therefore relies on migrant women as a source of labour for domestic services and care for older people (León, 2010). The use of private care services by IRMs is, however, largely unknown. One prior study by the author indicates some use of private domiciliary Spanish care services by British retired migrants, although language and cultural barriers were noted (Hall and Hardill, 2016). The same research also indicates the difficulties faced by British nationals in accessing residential care, with few public care 
homes operating in Spain. Even where British nationals are able to access care homes, language and cultural barriers persist. Gavanas and Calzada (2016) suggest that Swedish IRMs make use of (Swedish-speaking) private domiciliary and residential care services in Spain, but report that they are often expensive and that little or no financial government support is provided.

Some older migrants find support within the British community. Although British IRMs rarely integrate with their local Spanish community, many have strong friendship and support networks that involve the sharing of information and reciprocal help (Hall and Hardill, 2016). These networks provide solidarity and are underpinned by a mantra of caring whereby people check up on each other and offer support in times of distress or crisis, and so act like family (Oliver, 2008). Gavanas (2017) refers to these informal support networks that are situated on the premise of trust and reciprocity as the 'moral economy', which enable people to manage gaps in public provision and avoid the expense of the private care sector. A thriving (British-led) voluntary sector in Spain has also emerged that supports older and vulnerable British people with a range of different needs. Often seen as a social space, voluntary organisations such as Age Concern España and Age Care Association are an integral part of the British community in Spain (Haas, 2013; Hall and Hardill, 2016; Miller, 2019). However, little is known about the role of the voluntary sector in Spain in relation to care.

Transnational support from family and friends 'back home' may be an option when migrants are healthy, but when care needs set in, the ability to travel often diminishes. Occasional visits and virtual support are rarely a direct substitute for proximate care (Baldassar, 2014). Some IRMs exercise 'exit mobility' (Urry, 2007) or 'return migration' (Hall et al., 2017), relocating permanently to their home country when they reach the fourth age and their need for care, help and support increases (Giner et al., 2015; Ahmed and Hall, 2016; Hall and Hardill, 2016). Other IRMs may become 'stuck' in place, e.g. when health and/or financial resources prevent a return move (Hall et al., 2017). This is an increasingly common scenario, as older migrants who have lived in Spain for many years find themselves priced out of the UK housing market. It has been noted that lifestyle migrants may consolidate all of their economic resources to move abroad, and lack the financial means to return in later life (Benson and O'Reilly, 2009).

IRMs who stay in Spain when they have extensive care needs have recourse to only a limited patchwork of state, voluntary and privately funded care options. Some are able to call on local and transnational resources as their support needs increase, but the less well off or those lacking family support may fall through a transnational care gap (Gavanas and Calzada, 2016). Those who stay in Spain when they reach old age may have to devise complex strategies to obtain care that involve a mix of public, private and voluntary care provision (Hall and Hardill, 2016); although as Calzada notes (2017), their precise combination is determined by the economic, social and cultural resources of each individual.

\section{Precarity and ageing in Spain}

Precarity - and the state of precariousness - can be conceptualised as life worlds characterised by risk, uncertainty and insecurity (Waite, 2009; Grenier et al., 
2017). Following Kobayashi and Khan (2020), precarity is used in this paper to help understand the link between the micro and macro, and to capture a complex range of experiences and uncertainties that shape the everyday lives of older migrants and to foreground those experiences within a broader social setting. A focus on precarity requires exploration not only of the individual, but also of the socio-political context in which they are situated, including social protections and public safety nets (Grenier, 2020). Precarity can thus be heightened by external social and political changes or 'unsettling events' (Kilkey and Ryan, 2021), e.g. the disruption and uncertainty associated with Brexit that left EU migrants facing uncertainty over their welfare rights (Hall et al., 2020). The concept of precarity has often been used in analysing the situation of younger and economic migrants (Standing, 2011), but has more recently been applied to older people (Grenier et al., 2017, 2020; Grenier, 2020). In focusing on precarity among IRMs, this paper therefore extends an emerging body of literature, and allows for a better understanding of how the intersection of old age and migration can create enhanced levels of risk and insecurity.

Grenier (2020) helpfully differentiates between frailty and precarity in the context of care. Frailty and experiences of vulnerability centre on individual biomedical and functional risk, whereas precarity situates the experience within the broader societal context of responses to care. Care-related precarity is thus connected to the politics of accessing available care resources, including familial, social or public support. Access to care also connects to citizenship rights and as such can be conceptualised not only at a local or national level, but also as shaped by global social and economic forces (Fine, 2020). Older people's care needs must thus be considered against changing structures and conditions that include the match (or mismatch) between their needs, existing systems and available services (Grenier et al., 2020). Austerity measures have led to cuts in public social care provision across Europe that have further pushed care back to the family. This process has been particularly severe in Southern Europe, including Spain, where formal provision was already limited (Phillipson, 2020). In Spain, the scaling back of emergent public care provision since 2008, alongside a presumed existence of family care as discussed in the previous section, has led to limited provision of publicly funded care and arguably increased precarity for older people, Spaniards and non-Spaniards alike. However, for British migrants, care-related precarity may be more pronounced, due to the intersection of limited public safety nets, language barriers and distant family support.

British IRMs in Spain are not a homogenous group, and whilst often viewed as 'privileged' lifestyle migrants (Botterill, 2017), there are considerable socioeconomic differences between them (Oliver and O'Reilly, 2010). Variations in income level, ability to speak Spanish and access to social networks may lead to differential access to care and support, and thus to different degrees of precarity. For those already disadvantaged (e.g. with small incomes and/or limited support networks), the transition to a state of precarity in later life can happen quickly, especially for those who are isolated, ill and cannot afford or manage to move back to the home country (Gavanas and Calzada, 2016). This paper uses precarity as a lens for drawing attention to insecurity and risk in relation to migration, ageing and care, and enables a deeper understanding of the circumstances facing older 
Table 1. Interviewee characteristics

\begin{tabular}{ll}
\hline Marital status & 16 married, 13 widowed, 3 divorced, 2 single \\
\hline $\begin{array}{l}\text { Gender } \\
\text { Age }\end{array}$ & 24 female, 10 male \\
Living & $\begin{array}{l}16 \text { lived with a spouse, } 16 \text { lived alone, } 1 \text { with a live-in carer, } 1 \text { in a residential } \\
\text { hituation }\end{array}$ \\
hears in Spain & $3-47$ years, average 18.4 \\
\hline
\end{tabular}

Note: 1 . The 58-year-old was significantly younger than the other interviewees, but was included as he was an unpaid carer for his older, terminally ill wife. He also had his own health problems and the couple were using care services. All interviewees were retired with the exception of this interviewee who was undertaking some informal paid work on a part-time basis, as well as receiving his wife's pension.

migrants not only at individual, household and community levels, but within a broader social, economic and political context.

\section{Methods}

The data reported here are from a large UK-based study that aims to understand how care is planned, resourced, organised, delivered and experienced (see Acknowledgements), including for British nationals living outside the UK. The paper draws on qualitative interviews, conducted in February 2019, with 34 older British people living on the Costa del Sol, southern Spain (for interviewee characteristics, see Table 1). The Costa del Sol is located in the coastal area of Andalucía between Malaga in the east and Sotogrande in the west. All interviewees or the person they cared for had health problems and associated social care needs (i.e. they needed assistance with activities of daily living, maintaining independence and/ or social interaction), although not all were using care services. Health conditions of interviewees included arthritis, broken hips, Alzheimer's disease, vascular dementia and terminal cancer, and many were undergoing medical treatment. The interviewees included people in different care situations. Five received unpaid personal care from a family member and 12 provided personal care to a family member. Over half (18) paid for personal care and/or practical (e.g. shopping, cooking, cleaning) support in their own home. A further three interviewees lived in private flats within supported living facilities and one lived in a residential care home. Interviewees were not selected on the basis of precarity, i.e. it was not known before the interview if interviewees were in 'precarious situations' (Fine, 2020), rather, the interviews were used to understand the extent to which IRMs in Spain faced, or were likely to face, precarity in relation to their care needs.

Accessing older people with care needs in Spain was not straightforward. Recruiting participants via 'formal' channels, such as social services or town halls, was not possible for reasons of confidentiality, and because many IRMs have limited contact with public services. Instead, a convenience sample of interviewees were recruited via social media/newspaper advertisements $(\mathrm{N}=6)$, British-run care services $(\mathrm{N}=7)$, British social clubs $(\mathrm{N}=2)$ and voluntary organisations in Spain $(\mathrm{N}=19)$. To reduce sampling bias or pressure to take part, these 
organisations asked their members or clients if they would like to take part in an interview (either via newsletters, emails or face-to-face coffee mornings or meetings). Those who wished to take part made contact with the researcher directly. Representatives of the organisations were not present at the interviews, which mostly took place in interviewees' homes, although 13 were conducted in a café or at a coffee morning, one in hospital and one via Skype from the UK (as the interviewee was unavailable during the fieldwork period). Whilst it is recognised that this recruitment strategy meant interviewees were likely to receive support from a voluntary or care organisation, it also provided access to a population previously recognised as hard-to-reach and often isolated (Hall and Hardill, 2016). Interviewees could also be referred back to the voluntary/support services if they became distressed or if additional care or support needs emerged during the interview.

Ethical approval was obtained from the host institution and the study was undertaken with the welfare of participants in mind. All participants were provided with an information sheet and asked to sign a consent form prior to the interview, and were given the right to withdraw after the interview (one interviewee withdrew a few days after the interview and as per the research ethics, no reason was requested and the data were destroyed). All data were treated confidentially and anonymised through pseudonyms. Only those who had care needs (as defined above) or who were caring for someone with care needs were interviewed. All interviewees were considered to have capacity to provide consent.

Interviews took a narrative approach: recorded, transcribed stories, constructed into units for interpretation (Reissman, 2004; Ahmed and Rodgers, 2017). The narratives were used to understand the lives, lifestyles and experiences of individuals, the meanings attached to them and the context within which they were situated. The knowledge this produces is temporally, culturally and spatially specific, and constructed within a particular context and at a particular time. In the interviews, individuals and couples/families were asked about their lived experiences of ageing and care, which included experiences of both receiving and providing care. These narratives were put together to form a 'whole story' (Ahmed and Rodgers, 2017). Interviews centred on: ageing in Spain; accessing and receiving different types of formal care in Spain (state/private); providing or receiving unpaid care, including care and support from the voluntary and community sector, or from family/friends; and any barriers to care. A broad interview guide was used, with interviewees encouraged to 'tell their stories' and talk about issues that mattered to them. The average interview length was 45 minutes but varied considerably in length, ranging from 20 minutes to an hour and a quarter. The shorter interviews were with those who had considerable disabilities and/or could not speak for long periods, or with family carers who could not spend significant amounts of time away from their family member.

The interviews were audio recorded, transcribed and uploaded into NVivo 10 (QSR International, Melbourne) for coding. Analysis centred on the social, political and economic context that either facilitated or restricted access to care and support in their old age and the precarity of their circumstances. Data were analysed by the author using a process of thematic coding, with the first step involving the development of a coding framework (Attride-Stirling, 2001) underpinned by the research questions. Inductive coding was used to develop the themes and sub- 
themes through the extraction of salient, recurring or significant issues (Attride-Stirling, 2001). Selective coding was used to select quotes to outline the major themes (Fielding, 2008), some of which are presented below.

\section{Findings}

Care precarity lies at the intersection of public, private and informal care systems. The findings that follow focus on three dimensions of precarity: the political sphere, the economic sphere and the social sphere. The first section focuses on care policy and formal social protection for IRMs, the second on personal financial security, focusing particularly on the care market in Spain, and the third on informal social relationships and networks in Spain, including the role of the voluntary sector.

\section{The political sphere of precarity: social protection for IRMs}

Precarity draws attention to social protection and public safety nets (Grenier, 2020). As outlined above, in Spain, public medical (including hospital) care is free for British state pensioners, but social care is not. Many of the interviewees were aware that the Spanish social care system is underpinned by a 'familistic' (León and Migliavacca, 2013) model, and that subsequently there is limited public care, as Max explained:

In Spain all they say is family ... your family must look after you, which they do, when you look at it, the Spanish do. The social system here is so in the dark ages, there is no palliative care as such and what there is, is not worth having. (Max, 58, married)

Most interviewees did not have family (other than a partner/spouse) nearby to provide care. Almost half of the interviewees lived alone and most of the others lived with a spouse, who often had care needs. When asked about their access to publicly funded care in Spain, interviewees often made comparisons to the UK. Many recognised that social care is means-tested in the UK, but said that the care they would have expected in the UK was not available in Spain. This included district nursing, reablement and aftercare (which in the UK are services usually funded by the National Health Service). Chester spoke about his experience of care in hospital and after being discharged:

When you're in [hospital] it's lovely, once you're out there you are on your own ... There's no aftercare there's nothing like that ... they gave me a paper with all these tablets on, didn't tell me [what they were]. So now I'm like, 'What do I do?' (Chester, 72, married)

Precarity was engendered by an absence of formal frameworks for support and heightened by the fragmentation of family resources as a consequence of migration (Boddy et al., 2020). Very few interviewees had contacted Spanish social services, and where they had, additional barriers were reported, including long waiting lists: 
I contacted the Spanish social services. They were so slow, and the people I talked to ... really nice ladies, promising the earth. But I don't know how the Spanish people manage. (Jane, 80, married)

[I] tried [to contact social services], but they've told me that you have to book a person in about six years before. So, that's not much good is it? (Alice, 82, married)

Despite an awareness of the family-based care model in Spain, wider knowledge of the 'Spanish care system' by the IRMs, including entitlements to public support, was limited. Enid had been resident for 15 years (and thus entitled to access social services), but was unaware that she could apply for support:

There isn't really any free care here. I suppose if you're Spanish and you know the system there might be. (Enid, 75, married)

This reflects prior research indicating that migrants may not understand, or can be misinformed about, care systems, and so end up under-utilising them (Priebe et al., 2011). Language was widely reported as a fundamental barrier to accessing public care, as most interviewees spoke little Spanish. Interviewees explained how they could 'get by' in everyday interactions with Spaniards, but when it came to care, language and cultural barriers were a central factor in prohibiting access to care and support, thereby creating more precarious situations. Most interviewees said they did not want to contact social services because application forms are in Spanish and social workers and care workers rarely speak English. Kobayashi and Khan (2020) refer to limited language proficiency as a marker of precarity and, as seen here, can lead to migrants being marginalised from welfare services. Delia (aged 69), who cared for her husband, did not contact social services because she said 'there'd be no communication' between him and the care workers.

Accessing public social care in Spain was thus seen as challenging due to a combination of minimal state provision, insufficient knowledge and language barriers. Some interviewees considered returning to the UK when they developed care needs:

This is the care bit that worries us all ... what's going to happen to us? When you live alone, very scary here, very scary. I had seriously considered going back to the UK, because I was so afraid of what's going to happen when I get older. (May, 71, widowed)

However, as prior research has found (Giner et al., 2015; Hall and Hardill, 2016), returning is not straightforward and, for example, like all other immigrants to the UK, British nationals must pass the Habitual Residency Test (meaning it can take up to three months before any welfare, including from social services, can be obtained). Most interviewees, including May, decided to remain in Spain due to the legal and practical difficulties of return, and the worry of being unable to reintegrate as friends had often moved on since they left:

Our friends are either dead or they're so involved with grandchildren, that when we go home [to the UK] I don't feel as though I'm home anymore. (Trudy, 81, married) 
Other interviewees reported that they would like to return to the UK but had insufficient economic capital to do so. Rapidly rising house prices in the UK over the last few decades compared with Spain had priced many out of the UK housing market. Only a small number of interviewees had adequate financial resources (including property) to enable return. Others spoke about returning to live with family, indicating the importance of transnational ties:

When [husband] died his niece ... said, 'Anne don't be on your own, come and live with us [in the UK]', which was nice of her, and I'm sure that if the worst came to the worst I could go and live in their house. (Anne, 74, widowed)

Decisions to return were also influenced by broader social and legal structures, including Brexit, previously referred to as an 'unsettling event' that has created considerable uncertainty and precarity for migrants, particularly around their social protection (Kilkey and Ryan, 2021; Hall et al., 2020). Whilst the Withdrawal Agreement has secured IRM rights to health care, pension increments and other welfare entitlements (e.g. the continued exportability of Attendance Allowance for those already resident in Spain), during the research period (February 2019), interviewees spoke about feeling a sense of being betrayed by the UK Government and felt significant insecurity regarding their future in Spain. Many spoke about a potential scenario of being 'forced' to return to the UK if Brexit led to the removal of their welfare rights:

We might be forced to [return] if we get out of Brexit without a deal, well, it's possible that Spain will say, well, sorry, we're not going to pay for all your medication and your [medical] care full stop. And then our money would start to disappear rapidly. (Vera, 80, married)

Brexit thus introduced new and exacerbated existing precarities in the lives of IRMs due to the potential erosion of social rights and legal protections. It signalled increased uncertainties and insecurities, particularly in relation to health and financial security. Even before Brexit, IRMs had limited social protection for social care needs. Brexit exacerbated these challenges and increased socio-economic differences between migrants.

\section{The economic sphere of precarity: financial (in)security and the care market}

There was significant socio-economic diversity between interviewees. Some referred to themselves as 'comfortable' and having a 'steady income' through private pensions/investments and owning their own property. Others spoke about having 'just enough to live on' or 'struggling to get by' as they received only the British state pension and did not own any property. Around a third of the interviewees spoke about how a lack of money negatively affected their wellbeing. Some had experienced financial difficulties throughout their lives; others only encountered financial difficulties when they had to pay for additional care and support.

Those with higher incomes were able to make use of the growing number of private care services in Spain. Spanish care services that employ Spanish and (non-British) migrant care workers (León, 2010) were not widely utilised by any 
interviewees, who opted instead for care services run and staffed by British (or English-speaking) people. Such services that charge approximately $€ 15-20$ per hour, were reported to be significantly higher than Spanish care services (that charge from approximately $€ 8$ per hour). Interviewees, however, felt it was worth 'paying a bit extra' for a guaranteed English speaker. There are many British-run care organisations in the Costa del Sol; they are legally registered and provide personal care (washing, dressing), social support (e.g. taking someone out for the day) and practical help (e.g. transport and translation at hospitals). These organisations were also used by interviewees for aftercare following a stay in hospital, and for care in hospital, e.g. help with washing and eating, which, in Spain, are activities that family members are expected to provide (rather than nurses or health-care assistants as in UK hospitals). This familial care model in Spain again exposes key cultural differences in care provision between the UK and Spain. Henry reflected on paying a care worker to look after his wife when she was in hospital:

I remember when my wife was in hospital she said to me, 'I've got to have somebody here to come and help me', because I couldn't stay in the hospital all day long. So she said you'll have to get on to [care company] and see if they can get some care. So I did. I used to book them, and they used to go into the hospital and do things for her in hospital. (Henry, 85, widowed)

Having the economic capital to pay for care provided these interviewees with greater autonomy and control over their care needs, which in turn reduced their precarity. As Desmond (88, widowed) acknowledged, if people have got money, there is a lot of availability for caring'. However, those with a small income, such as the British state pension, found that paying for care and support, including, for example, transport to hospital, left them with very little money to live on:

My bank balance is just going down. I sold my house and the money's disappeared. It's expensive here. Did blood tests ... have to pay €60 each way for a taxi to Malaga hospital. You've got the taxi, you've got the carers five hours ... translator, it's just ... the money's disappeared. (Lucy, 79, divorced)

Lower living costs in Spain compared with the UK meant that many IRMs migrated to enable their small UK state pension to go further (see also Hall and Hardill, 2016). Lower living costs, and the warmer climate, allow IRMs to enjoy more social activities than in the UK, but as they age and their mobility declines, opportunities to socialise reduce and their low income becomes a pressing factor in their ability to access care. Some interviewees said that they were unable to afford the number of care hours they, or the person they cared for, needed to maintain their quality of life. Delia, who cares for her husband with Alzheimer's disease, paid a British care company for two to four hours per week to support them. She desperately needed more help, as she struggled to lift and thus to care for her husband, but could not afford more and found there was no additional financial support available. She even tried to re-mortgage her home to pay for care: 
I can't afford to [pay for any more care]. I mean it is, oh God, I even went to the bank about the mortgage. (Delia, 69, married)

One financial lifeline mentioned by some interviewees was UK Attendance Allowance, which was, at the time of interview, exportable to Spain (if eligibility criteria are met). Some interviewees, including Lucy, had made successful applications from Spain, which provided them with additional income that they could use to pay for care:

I was just about scraping through, but I have now been given disability, 400 [pounds] a month, which has helped a lot. (Lucy, 79, divorced)

These IRMs will continue to receive their Attendance Allowance under the Brexit Withdrawal Agreement; however, disability benefits including Attendance Allowance are not exportable for those who moved from 1 January 2021, leaving more newly arrived IRMs in a more financially precarious situation.

Other interviewees referred to seeking financial help from friends, family and other local people. Vera sought and received help from her local Spanish community to buy her husband a wheelchair:

We live here on a pension full stop and the last time [husband's] wheelchair it sort of half collapsed on me, so I said we have to have a new a wheelchair. I had to pay $£ 550$ for a wheelchair that I could lift into the car ... So I emailed [the mayor] and I said is there any chance of any help to pay for it? (Vera, 80, married)

Using informal social networks for financial or practical support with care needs was common among the IRMs. Precarity was therefore both exacerbated and reduced through a combination of formal and informal social protection. The next section focuses on informal social support and how community networks were instrumental in meeting the care needs of IRMs.

\section{The social sphere of precarity: informal care networks}

There is a strong sense of solidarity and reciprocity within the IRM community in Spain (Oliver, 2008, 2017) and there was evidence of collective and community solutions to address care gaps. Most interviewees spoke about relationships with friends, neighbours and acquaintances that not only offered socialisation, but also served to meet their emotional and practical care needs. For example, some interviewees spoke of their friends and/or neighbours who had driven them to hospital, translated at medical appointments, taken them shopping, brought cooked food to their house and picked up medication. Friends even took the place of a care worker, especially for those on low incomes. Maisie explained how she could not afford to pay her care agency for 24/7 care when she came out of hospital and so a friend stepped in:

I cancelled [care agency] only when I got [friend to help], because she only lives down the road and she said 'Look, day or night, just pick up the phone. Either I will come or [husband] will'. (Maisie, 73, married) 
Informal but paid care arrangements also existed within the IRM community. Many of the interviewees explained that they paid another local person (normally British or English-speaking) a small fee or in-kind payment to help meet their care needs. Frank (88, single) spoke about his Moroccan, English-speaking live-in carer who supports him with everyday activities, including dressing, shopping and cleaning. Frank has only a small UK state pension and so cannot afford to pay his carer a 'wage', but instead they reached an informal agreement where he covers his carer's living costs, e.g. housing, food and use of his car. This sort of informal 'home help' type of arrangement was common among interviewees who even referred to 'friends of friends' helping out with practical tasks such as with shopping, transport and help around the home. Ellen (70, married) often asks a friend or neighbour to take her to hospital and, as payment, she explained: 'You take them to lunch or buy them red wine or whatever.'

These examples of what has been referred to as 'liminal' care work (Daly et al., 2015) highlight the blended and often messy ways in which care work is ance formal and informal, paid and unpaid. The British-led voluntary and community sector in Spain also occupies a liminal space for IRMs. Voluntary organisations (e.g. Age Concern España, Age Care Association, Royal British Legion) provide IRMs with practical and social support, including with transport, translation and shopping, as well as emotional support during times of ill-health or crisis (see also Haas, 2013; Hall and Hardill, 2016). Volunteers also provided information on local care provision, including on Spanish social services and tele-alarm systems, and information on/help applying for Attendance Allowance, indicating their intersection with public support systems.

The voluntary organisations also offered more direct help with care, including organising and even paying for care services for those facing financial precarity. Max was 58 years old and a full-time carer for his 66-year-old wife with end-stage vascular dementia. She had considerable care needs and was confined to a hospital bed in the living room of their small rented home. Their income comprised a small pension and Attendance Allowance, which a British voluntary organisation helped them apply for. Max had been receiving help from a British friend, but due to a combination of his wife's considerable care needs and his own debilitating health condition, reached a point where he was unable to cope. They had no close family and their friendships had all but disappeared when his wife became ill. The above-mentioned voluntary organisation therefore organised and paid for a live-in care worker, as Max explained:

It's through [voluntary organisation], they're paying for [the care], because there is no way I can afford to do it, I would have to be on my own ... All we are living off at the moment is [wife]'s pension, Attendance Allowance and a little bit of a pension that I took early. It's not much. $€ 100$ a month. (Max, 58, married)

He went on to explain the precarity of their situation and the crucial role that the voluntary organisation and British care worker played in enabling him to cope with his own physical and emotional health risks, as well as in enabling his wife to have a peaceful death:

Without people like [voluntary organisation] and [care worker] ... I can't thank them enough, I really can't, because without them, [wife] wouldn't have the 
peacefulness for the end of her life, that I couldn't give her. Who is to say, if I hadn't had the care, I would have been here to help her anyway? It was like bailing out of a boat with a hole in your bucket, sort of thing, getting nowhere, fast. (Max, 58 , married)

The sense of precarity experienced by Max could be best described as 'teetering on the edge' (Standing, 2011: 20). For Max, the onset of care needs became a crucial turning point in amplifying the social risks and financial insecurities that had been produced over their lifecourse. The precarity of Max and his wife's situation had developed through the intersection of their declining health status, their limited financial security, weak family networks and minimum social protection. Max's story also shows how responses to precarity can involve the collective mobilisation of resources, as Max was dependent on a network of care and support that included friends, a voluntary organisation, care workers and the state. Such liminal care arrangements highlight the intersection of the formal and informal, paid and unpaid within the British IRM community.

\section{Discussion}

International retirement migration creates opportunities for older people to seek a better quality of life post-retirement (Benson and O'Reilly, 2009) and IRMs are often seen to occupy a privileged socio-economic position compared to other types of migrants. However, as IRMs age they face frailty, dependence and care needs that compromise previously mobile and active lifestyles. This study is the first to explore the strategies used by IRMs to access care in later life and extends the concept of precarity theoretically, using it to explore the intersection of migration, ageing and care. Whilst precarity has been widely utilised in relation to migration, it is rarely applied to ageing migrants. In the field of international retirement migration, prior research on care has instead tended to focus on the precarity of migrant care workers (Gavanas and Calzada, 2016) and the vulnerability of ageing IRMs (Hall and Hardill, 2016). Whilst the concepts of 'vulnerability' and 'frailty' are helpful to understand individual experiences of ageing and care, drawing on a lens of precarity helps situate individual (micro) experiences of care within broader (macro) political, economic and social spheres (Grenier, 2020). It is crucial to explore the risks and insecurities facing older migrants in relation to citizenship rights, welfare structures, care markets and social inequalities.

The lives of IRMs are situated betwixt and between the home (British) and host (Spanish) welfare states. A central argument in this paper is that (a lack of) citizenship rights and social protection can significantly contribute to care-related precarity for older migrants. For IRMs in Spain, the British welfare state funds the health-care costs of pensioners, but it does very little to support their social care needs. On the other hand, the Spanish welfare state is underpinned by a family care model, with emergent public social care provision scaled back since the 2008 economic crisis. Spaniards therefore rely on family, backed up by a market of low-paid (often migrant) care workers (León and Migliavacca, 2013). IRMs can therefore find themselves in a precarious situation and facing a care gap where the care provision they might need (or expect to receive) is insufficient. Whilst this is not a comparative study, interviewees spoke about cultural differences 
between the UK and Spain in relation to their expectations about care. The care they had expected (or previously received) in the UK (including non-medical care in hospital, aftercare, community-based social care and palliative care) was unavailable through the public system in Spain. Language barriers further impeded their access to public care systems.

One might assume that IRMs can access social protection by returning to their home welfare state. Indeed, returning to the UK when care needs arise has been reported to form part of the 'migration project' (Hall et al., 2017). However, return may only be an option for those who have maintained property in the home country or who have family to whom they can return. As such, the most precarious and at-risk groups are often unable to manage or afford to return (Gavanas and Calzada, 2016). Legal and structural barriers can also prohibit return. The Habitual Residency Test means that returning British nationals are not immediately entitled to social protection, which can in turn lead to precarious situations with IRMs becoming 'stuck' in place or alternatively returning to the UK but with minimal welfare rights for many months after arrival.

Brexit and COVID-19 are also likely to have exacerbated care precarity. Brexit was an 'unsettling event', introducing significant uncertainty into the lives of EU migrants, particularly in relation to the potential loss of welfare rights (Hall et al., 2020). Whilst the rights of those who moved to another EU country (and became legally resident) by 31 December 2020 have been secured under the Withdrawal Agreement, the same rights will not be available to those who move from January 2021. Whilst all of the interviewees in this study were legally resident in Spain, other research indicates that some IRMs do not register (Hall et al., 2021) and so will have minimal rights to both residency and welfare post-Brexit, leaving them in a more precarious state when they need care. This research was undertaken before the COVID-19 pandemic, but it is also likely that the pandemic has exacerbated or introduced precarity in the lives of IRMs. In Spain, COVID-19 cases were some of the highest in the world and the pandemic has highlighted the Spanish long-term care system's shortcomings, and the pressing need to develop a more community-based model (Zalakain and Davey, 2020). However, this is a long-term ambition and in the short term, access to care services, including those within the British community, are likely to have been impacted and care pushed even further into the family domain. Further, the transnational support that IRMs received from family in the UK through visits has been significantly impacted by travel restrictions, further increasing the isolation and therefore precarity of IRMs.

Care precarity, however, does not impact everyone equally and is created by a web of intersecting factors, including socio-economic status, migration/citizenship status, geographic location, age, health status, social networks and gender. An intersectionality approach highlights how individual circumstances are shaped by wider social inequalities and power structures to create an interplay of privileged and precarious situations. Whilst at first glance British IRMs may appear a homogeneous group, there are strong internal socio-economic distinctions. Some have greater access to resources than others, including financial and social capital. These inequalities may be less evident when IRMs are in the third age and are healthy, and for many, the initial move to Spain led to increased financial security (through lower living costs) and social capital (via new friendships and networks in Spain) 
compared to their previous life in the UK. Ageing and the need for care can, however, be a crucial turning point for migrants and one in which socio-economic diversity and precarity produced over the lifecourse is amplified, e.g. as a consequence of low income or limited support networks (Grenier, 2020; Kobayashi and Khan, 2020). The disparities between IRMs are therefore extended in relation to care and it is clear that IRMs who are dependent on welfare are in more precarious situations than those who have sufficient economic and social resources.

The precarity of IRMs therefore lies at the interface of formal and informal, paid and unpaid care. Whilst the market is frequently utilised to address short-term care needs, only a minority of IRMs are in an economically privileged position to purchase long-term care. When care needs set in, many IRMs were struggling to 'get by' with support from friends and community/voluntary organisations in Spain. There are a plethora of British-led voluntary and community organisations that provide solidarity, social support and practical help to IRMs (Hardill et al., 2005; Haas, 2013; Gavanas, 2017); however, this is the first study to identify the importance of these organisations in organising and even paying for care services. The support offered by volunteers often fill a critical 'care gap' and occupy the liminal space (Daly and Armstrong, 2016) between the public, private and informal sectors to reduce precarity. Informal networks of care also comprise friends and neighbours, who 'help each other out' during times of need by providing transport to hospital or providing aftercare; but these are often fragile and short-lived arrangements. The widespread use of British (or at least English-speaking) care services and voluntary organisations highlights that when it comes to care, having a shared socio-cultural and linguistic background is of crucial importance.

The care and support networks of IRMs are therefore multifaceted and often multi-directional, and underpinned by community self-organising activities. As the case of Max demonstrates, state and market resources are often overshadowed by the everyday support offered by mutual or collective solidary. The informality of care networks for many IRMs could represent what Gavanas (2017) calls the 'moral economy of care' that fills the gaps between unstable and shifting family, state and market solutions, and so addresses inequalities and therefore precarity. Following Waite (2009), the activities of the British community to 'rally around' indicate how precarity can also be viewed as a point of mobilisation, with the exertion of collective agency a response to overcome risk and insecurity. From this perspective, precarity can be a collective rather than individual condition, with collective agency within and across migrant communities helping to overcome precarious situations.

\section{Conclusion}

This paper has extended the concept of precarity to explore how the intersection of migration, ageing and care create new forms of risk and insecurity among older migrants. It has outlined the political, economic and social dimensions of precarity for British IRMs in Spain and shown how once stable and active retirement lifestyles can be replaced by more fragile life worlds with the onset of care needs. There are growing numbers of older IRMs facing care-related precarity, compounded by declining resources at an individual level, and the absence of formal structures of support and social protection. It has also indicated how the migrant 
community can be mobilised to provide a collective response to precarity, with informal relationships and voluntary organisations playing a crucial role in reducing the risk and insecurity of IRMs as they age. These findings have a wider application beyond the older British community in Spain (and other European destinations such as France and Italy). International retirement migration is a growing phenomenon, including the retirement of British and other Northern Europeans to destinations in, for example, South-East Asia where health, care and other support systems are less developed than in Europe (Botterill, 2017). The retirement of British nationals to destinations outside Europe may escalate post-Brexit as freedom of movement and some welfare exportability rights are withdrawn. Further quantitative and qualitative research is needed to: identify the scale and scope of international retirement migration in these regions; understand the nature of (formal and informal) care and support systems in these regions; and explore the extent to which the care needs of IRMs in these regions are being met.

This research has some limitations. The focus of the paper is on care in the home, and includes only one interviewee in residential care. Further qualitative research is needed to explore how British IRMs access and experience residential care in Spain. Further research is also needed that includes interviews with a wider set of social actors involved in the provision of care for British IRMs in Spain, including social workers and care workers/providers. Finally, this study focused on IRM experiences on the Costa del Sol, where there are established voluntary and private care networks that cater for IRMs. The findings therefore cannot be generalised to all areas of Spain, or to other retirement destinations including, for example, France, Portugal and Italy. Further qualitative research is recommended to understand the care and support needs of British IRMs in these destinations, particularly those living in remote areas with few IRM-led voluntary and private care services.

Acknowledgements. The author would like to thank the Sustainable Care research team for their ongoing support in carrying out the research for this paper. She would particularly like to thank Professor Sue Yeandle and Professor Majella Kilkey for providing comments on previous versions of this paper. The author gratefully acknowledges the support of the Economic and Social Research Council.

Financial support. This work was supported by the Economic and Social Research Council (award number ES/P009255/1, 'Sustainable Care: Connecting People and Systems', 2017-2021, Principal Investigator Sue Yeandle, University of Sheffield).

Ethical standards. Ethical approval for the study was secured through the Research Ethics Committee of the host university.

\section{References}

Ahmed A and Hall K (2016) Negotiating the challenges of ageing as a British migrant in Spain. GeroPsych 29, 105-114.

Ahmed A and Rogers M (2017) Polly's story: using structural narrative analysis to understand a trans migration journey. Qualitative Social Work 16, 224-239.

Arun S, Brahic B and Taylor S (2020) Global mobilities: united by dividing and accelerating precarities. Migration and Development 9, 1-7.

Attride-Stirling J (2001) Thematic networks: an analytic tool for qualitative research. Qualitative Research 1, 385-405.

Baldassar L (2014) Too sick to move: distant 'crisis' care in transnational families. International Review of Sociology 24, 391-405. 
Benson M and O'Reilly K (eds) (2009) Lifestyle Migration: Expectations, Aspirations and Experiences. Aldershot, UK: Ashgate.

Benton M (2017) Safe or Sorry? Prospects for Britons in the European Union After Brexit. Brussels: Migration Policy Institute Europe.

Boddy J, Bakketeig E and Østergaard J (2020) Navigating precarious times? The experience of young adults who have been in care in Norway, Denmark and England. Journal of Youth Studies 23, 291-306.

Botterill K (2017) Discordant lifestyle mobilities in East Asia: privilege and precarity of British retirement in Thailand. Population, Place and Space 23, e2011.

Calzada I (2017) Social protection without borders? The use of social services by retirement migrants living in Spain. Journal of Social Policy 47, 21-37.

Casado-Diaz MA (2006) Retiring to Spain: an analysis of differences among Northern European nationals. Journal of Ethnic and Migration Studies 32, 1321-1339.

Daly T and Armstrong P (2016) Liminal and invisible long-term care labour: Precarity in the face of austerity. Journal of Industrial Relations 58, 473-490.

Daly T, Armstrong P and Lowndes R (2015) Liminality in Ontario's long-term care facilities: Private companions' care work in the space 'betwixt and between'. Competition and Change 19, 246-263.

Fielding J (2008) Coding and managing data. In Gilbert GN (ed.), Researching Social Life, 3rd Edn. London: Sage, pp. 323-352.

Fine M (2020) Reconstructing dependency: precarity, precariousness and care in old age. In Grenier A, Phillipson C and Settersten R (eds), Precarity and Ageing: Understanding Insecurity and Risk in Later Life. Bristol, UK: Policy Press, pp. 169-190.

Gavanas A (2017) Swedish retirement migrant communities in Spain: privatization, informalization and moral economy filling transnational care gaps. Nordic Journal of Migration Research 7, 165-171.

Gavanas A and Calzada I (2016) Multiplex migration and aspects of precarization: Swedish retirement migrants to Spain and their service providers. Journal of Critical Sociology 42, 1003-1016.

Giner J, Hall K and Betty C (2015) Back to Brit: retired British migrants returning from Spain. Journal of Ethnic and Migration Studies 42, 797-815.

Grenier A (2020) Rereading frailty through a lens of precarity: an explication of politics and the human condition of vulnerability. In Grenier A, Phillipson C and Settersten R (eds), Precarity and Ageing: Understanding Insecurity and Risk in Later Life. Bristol, UK: Policy Press, pp. 69-90.

Grenier A, Phillipson C, Laliberte Rudman D, Hatzifilalithis S, Kobayashi K and Marier P (2017) Precarity in late life: understanding new forms of risk and insecurity. Journal of Aging Studies 43, 9-14.

Grenier A, Hatzifilalithis S, Laliberte-Rudman D, Kobayashi K, Marier P and Phillipson C (2020) Precarity and aging: a scoping review. The Gerontologist 60, e620-e632.

Haas H (2013) Volunteering in retirement migration: meanings and functions of charitable activities for older British residents in Spain. Ageing \& Society 33, 1374-1400.

Hall K and Hardill I (2016) Retirement migration, the 'other' story: caring for frail elderly British citizens in Spain. Ageing \& Society 36, 562-585.

Hall K, Betty C and Giner J (2017) To stay or to go? The motivations and experiences of older British returnees from Spain. In Vathi Z and King R (eds). Return Migration and Psychosocial Wellbeing. London: Routledge, pp. 221-239.

Hall K, Phillimore J, Grzymala-Kazlowska A, Vershinina N, Ögtem-Young Ö and Harris C (2020) Migration uncertainty in the context of Brexit: resource conservation tactics. Journal of Ethnic and Migration Studies. Available online doi:10.1080/1369183X.2020.1839398.

Hall K, Ono M and Kohno A (2021) British and Japanese international retirement migration and creative responses to health and care challenges: a bricolage perspective. Comparative Migration Studies 9, 7.

Hardill I, Spradberry J, Arnold-Boakes J and Marrugat LM (2005) Severe health and social care issues among British migrants who retire to Spain. Ageing \& Society 25, 769-783.

Huete R, Mantecon A and Estevez J (2013) Challenges in lifestyle migration research: reflections and findings about the Spanish crisis. Mobilities 8, 331-348.

Kilkey M and Ryan L (2021) Unsettling events: understanding migrants' responses to geopolitical transformative episodes through a life-course lens. International Migration Review 55, 227-253.

Kobayashi K and Khan M. (2020) Precarity, migration and ageing. In Grenier A, Phillipson C and Settersten R (eds). Precarity and Ageing: Understanding Insecurity and Risk in Later Life. Bristol, UK: Policy Press, pp. 115-146. 
Legido-Quigley $\mathbf{H}$ and McKee $\mathbf{M}$ (2012) Health and social fields in the context of lifestyle migration. Health and Place 18, 1209-1216.

Léon M (2010) Migration and care work in Spain: the domestic sector revisited. Social Policy and Society $\mathbf{9}$, 409-418.

León M and Migliavacca M (2013) Italy and Spain: still the case of familistic welfare models? Population Review 52, 25-42.

Michel S and Peng I (2012) All in the family? Migrants, nationhood, and care regimes in Asia and North America. Journal of European Social Policy 22, 406-418.

Miller RG (2019) (Un)settling home during the Brexit process. Population, Space and Place 25, e2203.

Oliver C (2008) Retirement Migration: Paradoxes of Ageing. London: Routledge.

Oliver C (2017) Peer-led care practices and 'community' formation in British retirement migration. Nordic Journal of Migration Research 7, 165-171.

Oliver C and O'Reilly K (2010) A Bourdieusian analysis of class and migration: habitus and the individualising process. Sociology 44, 49-66.

O'Reilly K (2000) The British on the Costa del Sol: Transnational Identities and Local Communities. London: Routledge.

O'Reilly K (2007) Intra-European migration and the mobility-enclosure dialectic. Sociology 41, 277-293.

O'Reilly K (2017) The British on the Costa del Sol 20 years on: a story of liquids and sediments. Nordic Journal of Migration Research 7, 139-147.

Phillipson C (2020) Austerity and precarity: individual and collective agency in later life. In Grenier A, Phillipson C and Settersten R (eds), Precarity and Ageing: Understanding Insecurity and Risk in Later Life. Bristol, UK: Policy Press, pp. 215-236.

Priebe S, Sandhu S, Dias S, Gaddani A, Greacen T, Ioannidid E, Kluge U, Krasnik A, Lamkadden M, Lorant V, Riera RP, Sarvary A, Soares J, Stankunas M, Strabmavr C, Wahlbeck K, Welbel M and Bogic M (2011) Good practice in health care for migrants: views and experiences of care professionals in 16 European countries. BMC Public Health 11, 187.

Reissman CK (2004) Narrative analysis. In Lewis-Beck MS, Bryman A and Liao TF (eds), The Sage Encyclopaedia of Social Science Research Methods, Vols 1-3. Thousand Oaks, CA: Sage, pp. 705-709.

Rodríguez Cabrero G, Codorniu JM, González de Durana AA, Marbán Gallego V and Moreno Fuentes FJ (2018) ESPN Thematic Report on Challenges in Long-term Care: Spain. Brussels: European Commission.

Standing G (2011) The Precariat. London: Bloomsbury.

Urry J (2007) Mobilities. Cambridge: Polity.

Waite L (2009) A place and space for a critical geography of precarity? Geography Compass 3, 412-433.

Zalakain J and Davey V (2020) The COVID-19 on Users of Long-term Care Services in Spain. LTCcovid, International Long-term Care Policy Network, CPEC-LSE. Available at https://tccovid.org/wp-content/ uploads/2020/05/LTCcovid-Spain-country-report-28-May-1.pdf.

Cite this article: Hall K (2021). Care precarity among older British migrants in Spain. Ageing \& Society 1-19. https://doi.org/10.1017/S0144686X21001392 